\title{
Central Administration of Lipopolysaccharide Induces Depressive-like Behavior in Vivo and Activates Brain Indoleamine 2,3 Dioxygenase In Murine Organotypic Hippocampal Slice Cultures
}

\author{
Xin Fu', Samantha M Zunich', Jason C O'Connor ${ }^{1}$, Annemieke Kavelaars ${ }^{1,2,3}$, Robert Dantzer ${ }^{1,2}$, Keith W Kelley ${ }^{1,2^{*}}$
}

\begin{abstract}
Background: Transient stimulation of the innate immune system by an intraperitoneal injection of lipopolysaccharide (LPS) activates peripheral and central expression of the tryptophan degrading enzyme indoleamine 2,3 dioxygenase (IDO) which mediates depressive-like behavior. It is unknown whether direct activation of the brain with LPS is sufficient to activate IDO and induce depressive-like behavior.
\end{abstract}

Methods: Sickness and depressive-like behavior in C57BL/6J mice were assessed by social exploration and the forced swim test, respectively. Expression of cytokines and IDO mRNA was measured by real-time RT-PCR and cytokine protein was measured by enzyme-linked immunosorbent assays (ELISAs). Enzymatic activity of IDO was estimated as the amount of kynurenine produced from tryptophan as determined by high pressure liquid chromatography (HPLC) with electrochemical detection.

Results: Intracerebroventricular (i.c.v.) administration of LPS (100 ng) increased steady-state transcripts of TNFa, IL-6 and the inducible isoform of nitric oxide synthase (iNOS) in the hippocampus in the absence of any change in IFNg mRNA. LPS also increased IDO expression and induced depressive-like behavior, as measured by increased duration of immobility in the forced swim test. The regulation of IDO expression was investigated using in situ organotypic hippocampal slice cultures (OHSCs) derived from brains of newborn C57BL/6J mice. In accordance with the in vivo data, addition of LPS $(10 \mathrm{ng} / \mathrm{ml})$ to the medium of OHSCs induced steady-state expression of mRNA transcripts for IDO that peaked at $6 \mathrm{~h}$ and translated into increased IDO enzymatic activity within $8 \mathrm{~h}$ postLPS. This activation of IDO by direct application of LPS was preceded by synthesis and secretion of TNFa and IL-6 protein and activation of iNOS while IFNg expression was undetectable.

Conclusion: These data establish that activation of the innate immune system in the brain is sufficient to activate IDO and induce depressive-like behavior in the absence of detectable IFNg. Targeting IDO itself may provide a novel therapy for inflammation-associated depression.

\section{Background}

Clinical and animal studies implicate systemic inflammation in the pathogenesis of major depressive disorders by activating immune-to-brain communication pathways [1-5]. Proinflammatory cytokines induce symptoms of sickness that correspond to a temporary reorganization

\footnotetext{
* Correspondence: kwkelley@illinois.edu
'Integrative Immunology and Behavior Program, Department of Animal

* Correspondence: kwkelley@illinois.edu
'Integrative Immunology and Behavior Program, Department of Animal Sciences, College of ACES, University of Illinois at Urbana-Champaign, Urbana, Illinois 61801, USA
}

(c) 2010 Fu et al; licensee BioMed Central Ltd. This is an Open Access article distributed under the terms of the Creative Commons Attribution License (http://creativecommons.org/licenses/by/2.0), which permits unrestricted use, distribution, and reproduction in any medium, provided the original work is properly cited.

of the organism's priorities to cope with infections. If the neuroimmune inflammatory response does not resolve, sickness behavior can culminate in depressivelike behavior $[2,6]$. Inflammation-induced depression is associated with activation of the tryptophan degrading enzyme indoleamine 2,3 dioxygenase (IDO) in both the brain and periphery. IDO is a ubiquitous enzyme that degrades tryptophan into kynurenine, which can decrease the bioavailability of tryptophan for the synthesis of serotonin [7-11]. The kynurenine/tryptophan 
ratio increases in the plasma and brain of patients and animals following both acute and chronic stimulation of the immune system [12-17]. Kynurenine can be further degraded into a number of neuroactive metabolites that act as agonists or antagonists of the NMDA receptor that can ultimately impact on glutamatergic neurotransmission [18-20].

Sickness is an adaptive response to infectious pathogens. Although sickness and depression can share symptoms, the similarities are only partial. Sickness rather than depression is fully reversible once the pathogen has been eliminated [2]. In both mice injected with lipopolysaccharide (LPS) or infected with Bacille CalmetteGuerin, depressive-like behavior remains after sickness behavior had abated [2]. Systemic administration of LPS is a well-established model to study behavioral and physiological responses following peripheral activation of the immune system. Sickness behavior peaks in the first 2 to $6 \mathrm{~h}$ following intraperitonal injection of LPS and gradually returns to normal $[2,14,21]$. Twenty four hours after treatment, when sickness behavior has diminished, depressive-like behavior still remains, as measured by increased immobility in both the forced swim test (FST) and tail suspension test and decreased preference for a sweetened solution $[2,14,21]$. These findings indicate that the LPS model of peripheral acute immune activation can dissociate sickness from depression.

Activation of IDO is a key event in the switch from sickness to depression. Blockade of cytokine production and IDO activation by administration of the anti-inflammatory tetracycline derivative minocycline prevents both LPS-induced sickness behavior and depressive-like behavior [14,22]. Administration of the IDO competitive inhibitor 1-methyl tryptophan abrogates development of LPS-induced depressive-like behavior without altering LPS-induced expression of proinflammatory cytokines and the development of sickness behavior [14].

In all the experiments carried out to date with systemic administration of LPS, IDO is activated both peripherally and in the brain. Peripherally activated IDO produces large quantities of kynurenine that can enter the brain via the same transporter as that for tryptophan $[23,24]$. This is important because peripherally administered kynurenine can induce depressive-like behavior in naive mice [14]. Although IDO is predominantly expressed in peripheral organs such as the lungs, it is also present in the brain where it can be activated by immune and non-immune stimuli [2]. However, the exact brain structures in situ where IDO is activated are less well known. Classic neurocircuitry of depression often refers to cortical-striatal-limbic networks of neural circuits that involve the sub-genual anterior cingulate cortex [25]. However, it is less appreciated that the hippocampus is another brain area that plays a role in the pathophysiology of major depressive disorders. It has been extensively studied in patients with mood disorders $[26,27]$ and is an important structure in the neurogenesis theory of depression $[26,28]$. In mice, the hippocampus is also related to depressive-like behavior $[21,29]$. Indeed, IDO is activated in the mouse [22,29,30] and rat [31] hippocampus following systemic administration of LPS. It is not yet known whether LPS administered directly in the cerebral ventricles is able to activate IDO in the hippocampus concomitantly with its ability to induce depressive-like behavior. Therefore, one of the questions we sought to answer is whether activation of IDO in the brain is sufficient to induce depressive-like behavior.

In order to study the mechanisms involved in the activation of IDO by central administration of LPS, we used organotypic hippocampal slice cultures (OHSCs) that have the advantage of preserving the basal cellular and connective organization of this brain area and several fundamental in vivo-like characteristics such as glialneuronal interactions $[32,33]$. This preparation has previously been used for studying the detrimental effects of proinflammatory cytokines on long-term potentiation in the rat system [34,35]. We show for the first time that centrally administered LPS is sufficient to activate IDO in the hippocampus and induce depressive-like behavior. Using organotypic hippocampal slice cultures we further demonstrate that this brain area responds to LPS by increased expression of IDO and cytokines, followed by activation of IDO. Finally, both the in vivo and in situ data support the idea that IDO can be regulated in an IFNg-independent manner [36,37]. These new findings point to the role of brain IDO in inflammation-induced depression.

\section{Methods \\ Reagents}

LPS was from Escherichia coli 0127:B8 (cat\# L-3137). Heat-inactivated horse serum (cat\# SH30074.03), Hank's balanced salt solution (HBSS, cat\# SH30030.03) and MEM (cat\# SH30024.02) were all from Hyclone. Gey's balanced salt solution (GBSS, cat\# G9779) was from Sigma. D-glucose (cat\# 15023-021) was from GibcoBRL and propidium iodide (PI, cat\# P3566) was from Molecular Probes Inc. (Eugene, OR). Kits for enzyme-linked immunosorbent assay (ELISA) were from R\&D Systems (Wiesbaden, DE). TRIzol reagent was from Invitrogen Life Technologies (Carlsbad, CA). Reagents for RT-PCR were all from Applied Biosystems as follows: Ambion (cat\# 1710) reverse transcriptase kit, Ambion's DNAfree $^{\mathrm{Tu}}$ DNase treatment and removal reagents (cat\# AM1906), RT-PCR primers for TNFa (cat\# Mm00443258_m1), IL-6 (cat\# Mm00446190_m1), IFNg 
(cat\# Mm00801778_m1), IDO (cat\# Mm00492586_m1), the inducible isoform of nitric oxide synthase (iNOS) (cat\# Mm00440485_m1) and glyceraldehyde-3-phosphate dehydrogenase (GAPDH; cat\# Mm999999_g1). The protease inhibitor cocktail (cat\# P2714) was from Sigma.

\section{Mice}

All animal care and use procedures were conducted in accordance with the Guide for the Care and Use of Laboratory Animals (National Research Council) and approved by the Institutional Animal Care and Use Committee. Experiments conducted in vivo were performed on 8-12-week-old male C57BL/6J mice obtained from a colony raised in our laboratory. Mice were individually housed in standard shoebox cages, with wood shavings as litter, in a temperature- $\left(23^{\circ} \mathrm{C}\right)$ and humidity- (45-55\%) controlled environment with a $12 / 12 \mathrm{~h}$ modified dark-light cycle (lights on 10:00 P.M.-10:00 A. M.). Food and water were available ad libitum.

\section{Intracerebroventricular (i.c.v.) Cannulation}

A stainless steel guide cannula (23-gauge, $7 \mathrm{~mm}$ length) was surgically implanted unilaterally $0.5 \mathrm{~mm}$ above the lateral ventricle of the brain, as previously described [38]. After anesthetizing with ketamine and xylazine ( $1 \mathrm{mg}$ and $0.1 \mathrm{mg} / 10 \mathrm{~g}$ body weight i.p., respectively), mice were secured in a Kopf stereotaxic instrument (Tujunga, CA, USA). Coordinates for placement of the guide cannula were $1 \mathrm{~mm}$ posterior to bregma, $1.6 \mathrm{~mm}$ lateral and $2.0 \mathrm{~mm}$ below the skull surface at the point of entry. Mice were allowed to recover a minimum of 7 days before treatment and initiation of behavioral tests. After recovery, mice were slowly injected over $1 \mathrm{~min}$ i.c.v. with sterile saline or LPS (100 ng) in a volume of $1 \mu$ l. This dose of LPS was selected on its ability to reliably induce sickness behavior [37-39]. The cannula was left in place for 1 min following injection.

\section{Behavioral Experiments}

All behavioral experiments were performed during the first $4 \mathrm{~h}$ of the dark phase of the light cycle and were video taped.

\section{Social exploration behavior}

Social exploration was carried out before and then 4, 8, and $24 \mathrm{~h}$ post i.c.v. injection using a protected novel juvenile that was introduced into the test subject's home cage for a five-min period. Social behavior was determined as the amount of time that the experimental subject spent investigating the juvenile [38].

\section{Forced swim test}

The forced swim test was conducted at $24 \mathrm{~h}$ post i.c.v. injection for a six-min period. Immobility was defined as passive floating behavior or any movement necessary for the mouse to keep its head above water, as described previously [30].

\section{Organotypic Hippocampal Slice Cultures}

Hippocampal slice cultures were prepared using the static interface culture method [39]. Briefly, 6- to 8-day-old C57BL/6J mice were euthanized by decapitation. The brains and meninges were removed, followed by separation of the hippocampus from both hemispheres. Hippocampi were dissected and transverse slices $(350 \mu \mathrm{m}$ in thickness) were prepared with a Mcllwain tissue chopper (Campden Instruments Ltd, UK). Slices were placed for $1 \mathrm{~h}$ at $4^{\circ} \mathrm{C}$ into GBSS supplemented with $2 \mathrm{mg} / \mathrm{ml}$ D-glucose and were then transferred onto porous $(0.4$ $\mu \mathrm{m})$ transparent membrane inserts $(30 \mathrm{~mm}$ in diameter; Millipore) with five slices on each insert. Inserts were then placed into six-well culture plates. Each well contained $1.2 \mathrm{ml}$ of nutrient medium composed of $25 \%$ heat-inactivated horse serum, 25\% HBSS and 50\% MEM, supplemented with $25 \mathrm{mM}$ D-glucose. Neither antibiotics nor anti-mitotics were used. Plates were maintained in a humidified $\mathrm{CO}_{2}$ incubator $\left(5 \% \mathrm{CO}_{2}\right.$, $95 \%$ atmospheric air) at $37^{\circ} \mathrm{C}$. Medium was changed every 2-3 days. The MEM medium was changed so that it contained only $5 \%$ horse serum and $25 \mathrm{mM}$ D-glucose on the day that LPS was added. At various times following addition of LPS, supernatants were collected and stored at $-80^{\circ} \mathrm{C}$ for measurement of cytokines. Slices were washed twice with cold PBS and stored at $-80^{\circ} \mathrm{C}$ for isolation of total cellular RNA and determination of IDO enzymatic activity.

\section{Slice staining}

Brain slices were stained at several times after sectioning by adding PI to label dead cells. Slices were incubated at $37^{\circ} \mathrm{C}$ for $30 \mathrm{~min}$ in $2 \mu \mathrm{M}$ PI. Slices were then imaged using an Axiovert 40 CFL microscope equipped with Axio CamMR using a $2.5 \times$ objective. Measurement of the intensity of PI staining was quantified using AxioVision.

\section{Reverse transcription and Real-time RT-PCR}

Total cellular RNA from the hippocampus and cultured slices was extracted in TRIzol reagent, as previously described [16]. Total mRNA (1-2 $\mu \mathrm{g})$ was reverse transcribed to cDNA using reverse transcriptase kits from Ambion. Samples were run in duplicate. Data were analyzed using the comparative threshold cycle method, as described elsewhere (Applied Biosystems User Bulletin no.2).

\section{Enzyme-linked immunosorbent assays (ELISAs)}

TNFa and IL-6 were measured with validated specific ELISA assays according to the manufacturer's 
instructions. Briefly, $100 \mu \mathrm{l}$ of each sample was added in duplicate to ELISA plates pre-coated with an anti-TNFa or IL-6 capture antibody. Recombinant murine TNFa and IL- 6 standards ranged from 0 to $1,000 \mathrm{pg} / \mathrm{ml}$. The lower assay limit of detection was $16 \mathrm{pg} / \mathrm{ml}$. Absorbance was measured on an OPTImax ELISA plate reader. TNFa and IL-6 concentrations were expressed as picograms per milliliter.

\section{Determination of IDO activity}

IDO activity was measured as previously described [40], with minor modifications. Briefly, slices were disrupted with ice-cold lysing buffer $(140 \mathrm{mM} \mathrm{KCl}, 20 \mathrm{mM}$ potassium phosphate buffer, $\mathrm{pH}$ 7.0) with a cocktail of protease inhibitors. After centrifugation of the homogenates $\left(13,000 \times g, 10 \mathrm{~min}, 4^{\circ} \mathrm{C}\right)$, supernatants were incubated for $1 \mathrm{~h}$ at $37^{\circ} \mathrm{C}$ in the following reaction mixture: 0.4 $\mathrm{mM}$ L-TRP, $20 \mathrm{mM}$ ascorbate, $10 \mu \mathrm{M}$ methylene blue, $100 \mu \mathrm{g}$ catalase in $50 \mathrm{mM}$ phosphate buffer, $\mathrm{pH} 6.5$. The reaction was stopped by addition of $10 \%$ sulfosalicylic acid solution (SSA), followed by incubation for 30 min at $50^{\circ} \mathrm{C}$ to convert $\mathrm{N}$-formylkynurenine to L-kynurenine $(\mathrm{L}-\mathrm{KYN})$. After centrifugation $(13,000 \times g, 10 \mathrm{~min}$, $\left.4^{\circ} \mathrm{C}\right)$ and ultrafiltration $(0.2 \mu \mathrm{M}$ filter tubes), the amount of L-KYN produced from TRP was determined by High Pressure Liquid Chromatography (HPLC) with electrochemical detection, as previously described [14]. Enzymatic activity was expressed as the product content per hour per milligram of protein.

\section{Statistical analysis}

Data from social exploration were analyzed using a twoway (treatment $x$ time) ANOVA with repeated measures on the time factor. Data from other experiments were analyzed using a one-way (treatment) ANOVA, followed by a Fisher's LSD post hoc test if the main effect was significant. All data are presented as means \pm SEM. Differences were considered significant if the probability reached a level of 0.05 or smaller.

\section{Results}

Central LPS challenge induces an episode of sickness behavior followed by depressive-like behavior

Peripheral LPS injection causes depressive-like behavior at $24 \mathrm{~h}$ in the absence of sickness response [14,21], so we sought to determine if similar behavioral changes could be induced by centrally administered LPS at a dose (100 ng) that we previously established to induce sickness behavior in both CD1 [41] and C57BL/6J $[42,43]$ mice. LPS-induced sickness was measured by assessing body weight and social exploration. As expected, i.c.v. administration of LPS induced a significant reduction in body weight $6 \mathrm{~h}$ after LPS injection compared to saline-treated controls $(-0.4 \pm 0.3(\mathrm{n}=4)$ vs. $0.5 \pm 0.1 \mathrm{~g}(\mathrm{n}=5) ; p<0.05)$. LPS reduced social exploration in a time-dependent manner (treatment $x$ time: $p<0.01)$. Social exploration was reduced at $4 \mathrm{~h}(p$ $<0.01)$ and $8 \mathrm{~h}(p<0.05)$, returning to baseline exploration by $24 \mathrm{~h}$ after i.c.v. injection of LPS (Fig. 1A). In
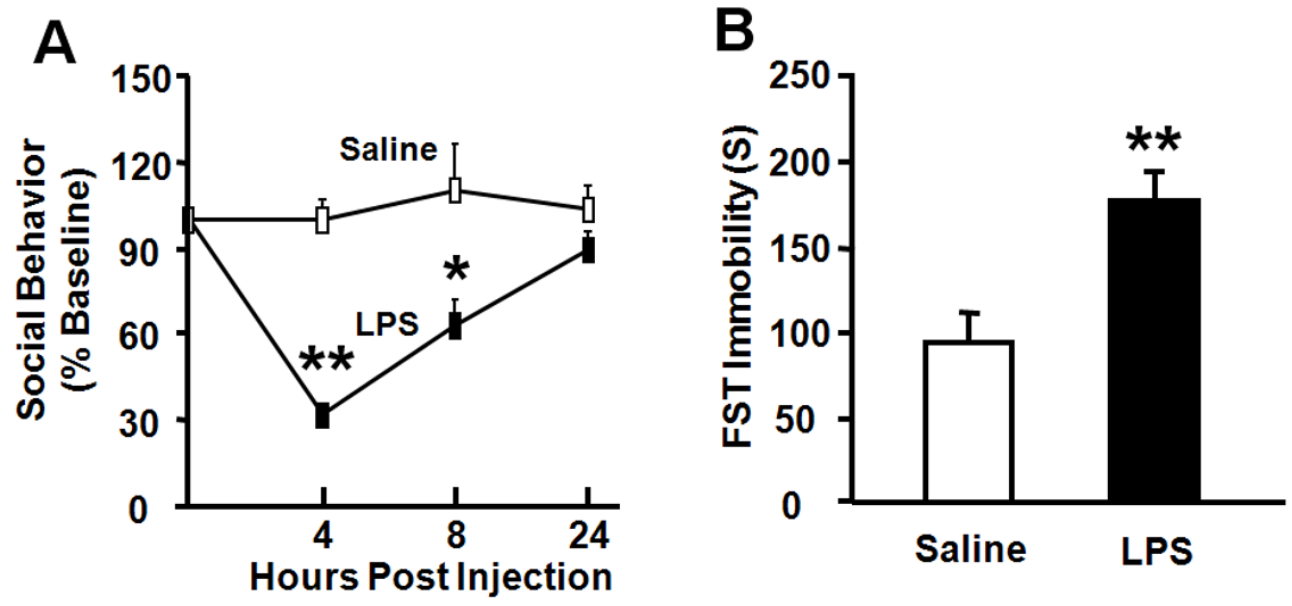

Figure 1 LPS administered via the i.c.v. route induces both sickness and depressive-like behavior. Mice were injected i.c.V. with either saline or LPS (100 ng). (A) Social behavior was measured during a 5 min period at 0, 4, 8 and $24 \mathrm{~h}$ following LPS injection. (B) Duration of immobility was quantified during a 6 min forced swim test that was recorded $24 \mathrm{~h}$ following administration of LPS. Data represent mean \pm SEM ( $n=4-6$ mice/group). ${ }^{*} p<0.05,{ }^{* *} p<0.01$ compared to saline. 
contrast, LPS increased immobility in the FST at $24 \mathrm{~h}$ post-treatment (Fig. 1B, $p<0.01$ ). Collectively, these data establish that acute activation of the central innate immune system with LPS in mice induces depressivelike behavior that does not overlap with sickness behavior.

\section{Central LPS challenge induces IDO, cytokine and iNOS expression in the hippocampus}

We have established that IDO and cytokine expression in the hippocampus of mice injected i.p. with LPS peaks within $6 \mathrm{~h}$ [29]. Therefore, the hippocampus was collected at the $6 \mathrm{~h}$ time point to determine the effects of LPS injected i.c.v. on the brain. Although IDO mRNA was undetectable in saline-treated mice, its expression increased significantly following central injection of LPS $(p<0.05)$ (Fig. 2A). LPS also increased TNFa $(p<0.01$; Fig. 2B), IL-6 ( $p<0.01$; Fig. $2 \mathrm{C})$, and iNOS $(p<0.05$; Fig. 2D) mRNA expression compared to saline-injected controls. LPS did not cause a statistically significant increase in IFNg mRNA expression (data not shown). These results indicate that centrally administered LPS activates brain cytokine signaling and increases brain IDO expression.

\section{Hippocampal slices largely recover from explantation by} day 7 in tissue culture

In order to investigate the mechanisms responsible for inflammation-induced depression, organotypic cultures of hippocampal slices were prepared from 6 to 8-dayold C57BL/6J mice. Preparation of murine hippocampal slices from postnatal brain requires cutting the hippocampus. We reasoned that the trauma caused by removal of afferents and efferents induced by the transversal slicing of hippocampus would cause an acute, but not chronic, inflammatory reaction. In order to assess the length of time required by OHSCs to recover, we collected both tissue slices and media at various time points to measure mRNA expression and protein levels of proinflammatory cytokines using real-
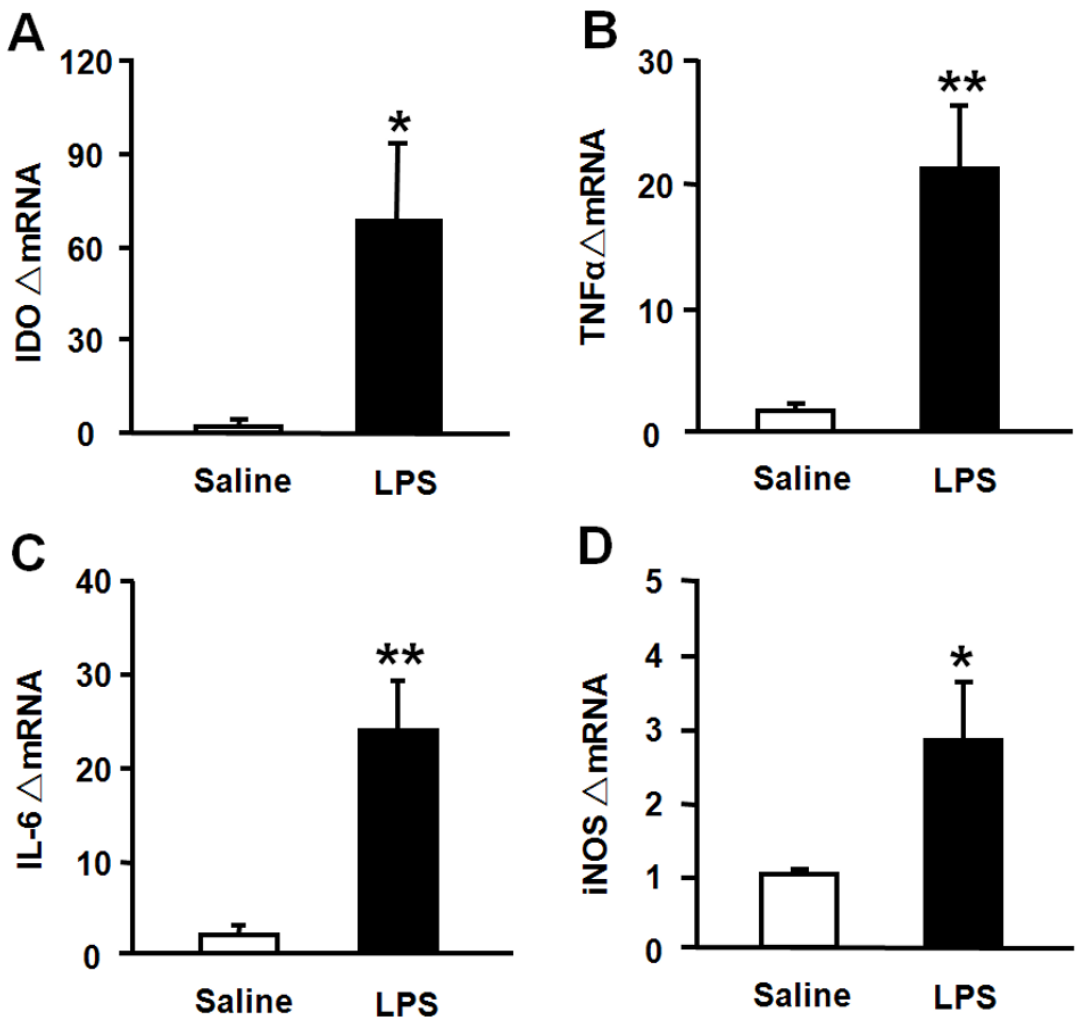

Figure 2 Central administration of LPS induces (A) IDO, (B) TNF $\alpha$, (C) IL-6 and (D) iNOS mRNA upregulation in the hippocampus. Mice were injected i.c.v. with either saline or LPS (100 ng) and the hippocampi were collected $6 \mathrm{~h}$ later. Steady-state expression of mRNA transcripts was measured by real-time RT-PCR. Average Ct values for LPS-treated mice were as follows: IDO = $33.0 \pm 0.4 ;$ TNFa $=23.3 \pm 0.4 ; \mathrm{IL}-6=24.2 \pm$ 0.4 ; iNOS $=28.0 \pm 0.3$. Data represent mean \pm SEM ( $n=4-5$ mice/group). ${ }^{*} p<0.05,{ }^{* *} p<0.01$ compared to saline. 
time RT-PCR and ELISA, respectively. LPS $(10 \mathrm{ng} / \mathrm{ml}$; $6 \mathrm{~h}$ treatment) was used as a positive control to treat OHSCs on day 10.

Immediately after transversal slicing on day 0 , mRNA from hippocampi was isolated. Although mRNA for TNFa, IL- 6 and iNOS could be detected immediately after slicing on day 0 , the amount was extremely low, particularly compared to the amount induced by LPS later in culture (Fig. 3). Indeed, after 10 days in culture, treatment with LPS dramatically increased expression of TNFa, IL- 6 and iNOS mRNA and induced roughly a nanogram per milliliter secretion of TNFa and IL-6 protein in the culture medium (Fig. 3). The amount of mRNA and protein caused by transversal slicing was minimal compared to treatment with LPS, but nonetheless, was detectable in several instances. For example, TNFa mRNA increased on both days 1 and $3(p<0.01)$ after slicing, but it returned to low but detectable levels by day 7 . However, the increase in amplified mRNA for TNFa was not accompanied by any detectable TNFa released into the medium at any time point. There was a temporary increase in IL-6 mRNA on day 1 (Fig. 3, $p<0.01)$. IL-6 protein in the culture medium was significantly increased on days 1 and $3(p<0.01)$. Expression of iNOS mRNA was only slightly increased (3-fold; $p<0.01$ ) on day 1 . This modest increase in iNOS mRNA was not associated with any increase in nitrite levels in the culture medium, as measured by Griess reaction (data not shown).

The viability of OHSCs was determined by PI staining [44]. As shown in Fig. 4, dead/dying cells could be detected in the dentate gyrus (DG), CA1 and CA3 regions $(\mathrm{p}<0.01)$ during the first 3 days of OHSCs culture. This was followed by a gradual decline in the proportion of PI-positive cells. Quantitative analysis confirmed that PI uptake significantly increased on day
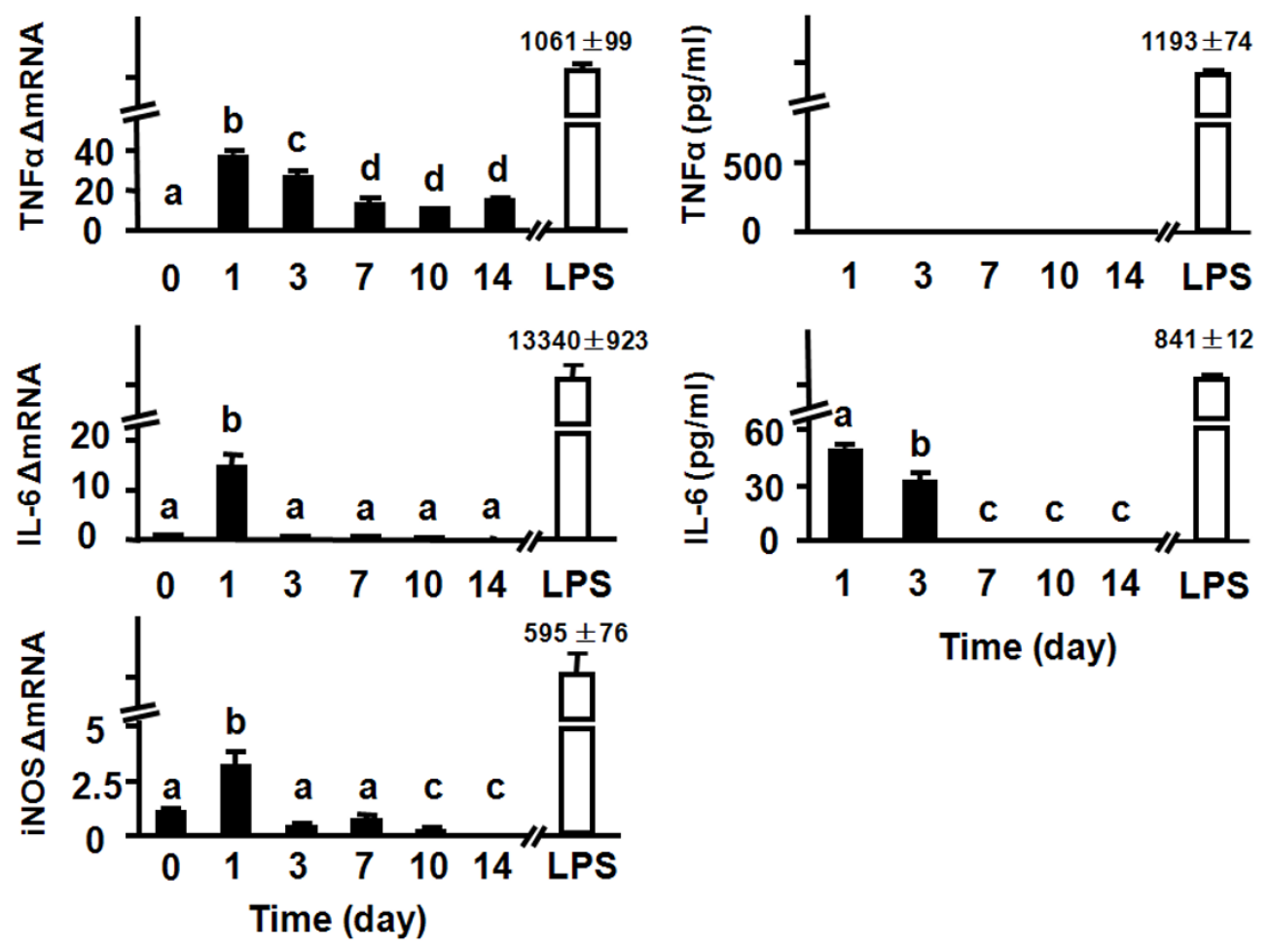

Figure 3 Proinflammatory cytokines and iNOS expression in hippocampal slices at the mRNA and protein level. Day 0 represents freshly-isolated hippocampi that were subjected to transversal slicing and mRNA being prepared immediately following slicing. Culture media and slice tissue were collected on days 1, 3, 7, 10 and 14 after the start of the culture. LPS $(10 \mathrm{ng} / \mathrm{ml})$ was used as a positive control on day 10 , with mRNA and protein being measured $6 \mathrm{~h}$ later. Steady-state expression of mRNA transcripts was measured by real-time RT-PCR, and proinflammatory cytokines in the media were measured by ELISA. Average Ct values for at 1, 3, 7, 10 and 14 days for each mRNA species were, respectively: TNFa: $27.6 \pm 0.7,27.8 \pm 0.5,29.0 \pm 0.3,29.1 \pm 0.5,28.7 \pm 0.6$; IL-6: $30.7 \pm 0.4,34.8 \pm 0.2,36.1 \pm 0.9,35.8 \pm 0.8,36.6 \pm 1.1$; iNOS: 28.8 $\pm 0.8,31.8 \pm 0.8,31.1 \pm 1.0,32.9 \pm 0.3,35.5 \pm 0.8$. Data represent the mean \pm SEM ( $n=3$ in each group). Bars labeled with different letters ( $a, b$, c or d) are significantly different from each other at $p<0.05$. 

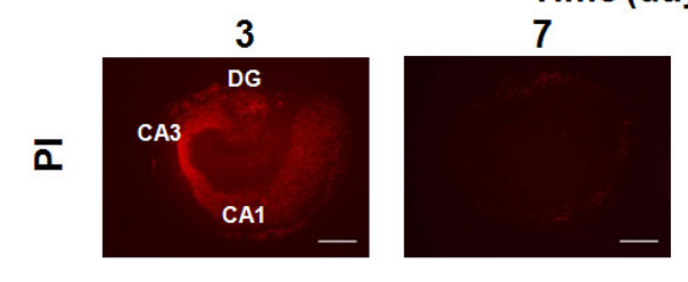

Time (day in vitro)
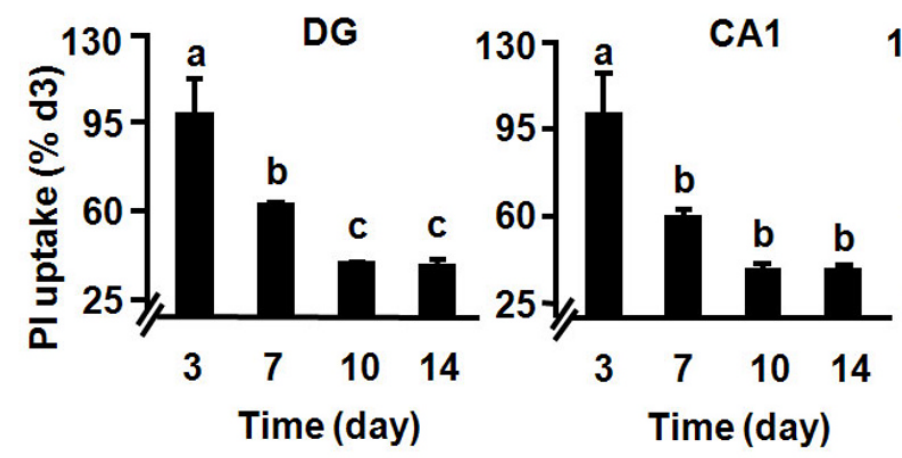

14

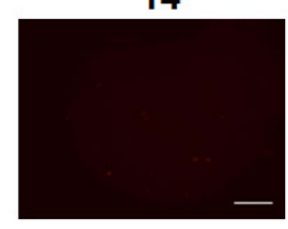

CA3

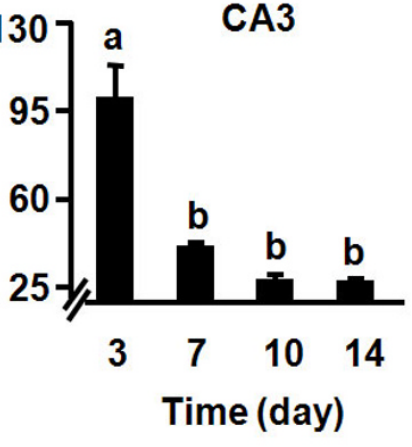

Figure 4 Time course of cell death in OHSCs. The OHSCs were treated with PI at different time points after the start of culture. Red fluorescence indicates the dead-cell population using PI staining. Bars represent the mean \pm SEM ( $n=3$ in each group). Bars labeled with different letters $(\mathrm{a}, \mathrm{b}$ or $\mathrm{c}$ ) are significantly different from each other at $p<0.05$. Scale bar $=500 \mu \mathrm{m}$.

$3(p<0.01)$ and then remained at rather low levels from days 7 through 14. The OHSCs responded very well to LPS at day 10 (Fig. 3), so the decline in proinflammatory cytokine expression that occurred with increasing time in culture was very unlikely to have been caused by cell death. Collectively, results of these experiments confirm that transversal slicing of the hippocampus causes an acute inflammatory response. These data also establish that OHSCs almost entirely recover from the explantation procedure within 7 days.

\section{Organotypic hippocampal slice cultures respond to LPS} by increased expression of proinflammatory cytokines Based on the in vivo response to central injection of LPS (Fig. 2), the time point of $6 \mathrm{~h}$ was selected for carrying out dose-response experiments to determine the effect of LPS on cytokine expression. Slices were exposed to 1 , 10 and $100 \mathrm{ng} / \mathrm{ml}$ of LPS on day 10 in culture. As shown in Fig. 5A, LPS increased TNFa and IL-6 production at both the mRNA $(p<0.05)$ and protein $(p<0.01)$ levels in a dose-dependent manner, with a maximum at $10 \mathrm{ng} / \mathrm{ml}$. In control cultures containing medium alone, neither TNFa nor IL-6 could be detected. iNOS mRNA reached a maximum at $100 \mathrm{ng} / \mathrm{ml}$ LPS $(p<0.01)$ but this was not associated with a detectable increase in nitrite levels at the $6 \mathrm{~h}$ time point (data not shown).
Nitrite levels remain undetectable in control OHSCs through at least 13 days in culture. Following LPS stimulation, nitrites begin to rise to detectable levels only after $48 \mathrm{~h}$, which allows adequate amounts to accumulate in the medium (data not shown).

For kinetic studies, OHSCs were exposed to $10 \mathrm{ng} / \mathrm{ml}$ LPS for 6, 12, 18 and $24 \mathrm{~h}$ on day 10 of culture. As shown in Fig. 5B, the greatest expression of both mRNA and protein for TNFa occurred at $6 \mathrm{~h}(p<0.01)$. In contrast, IL- 6 mRNA peaked at $6 \mathrm{~h}(p<0.01)$ and gradually returned to the control level at $24 \mathrm{~h}$. IL- 6 concentration in the culture medium increased after $6 \mathrm{~h}(p<0.01)$ and reached a maximum at $24 \mathrm{~h}(p<0.01)$. iNOS mRNA increased at $6 \mathrm{~h}(p<0.01)$ and peaked at $12 \mathrm{~h}$ $(p<0.01)$, but there was no concomitant increase in nitrite levels at any time point. These results reflect the capability of OHSCs to respond to inflammatory stimuli in a manner similar to that which occurs in vivo, indicating that OHSCs represent a reliable and valuable model for investigating neuroimmune interactions in a mouse system.

\section{LPS induces expression of IDO in the absence of IFN $\gamma$ transcripts in murine OHSCs}

We recently established that LPS induces expression of IDO in primary murine microglial cells in the absence 

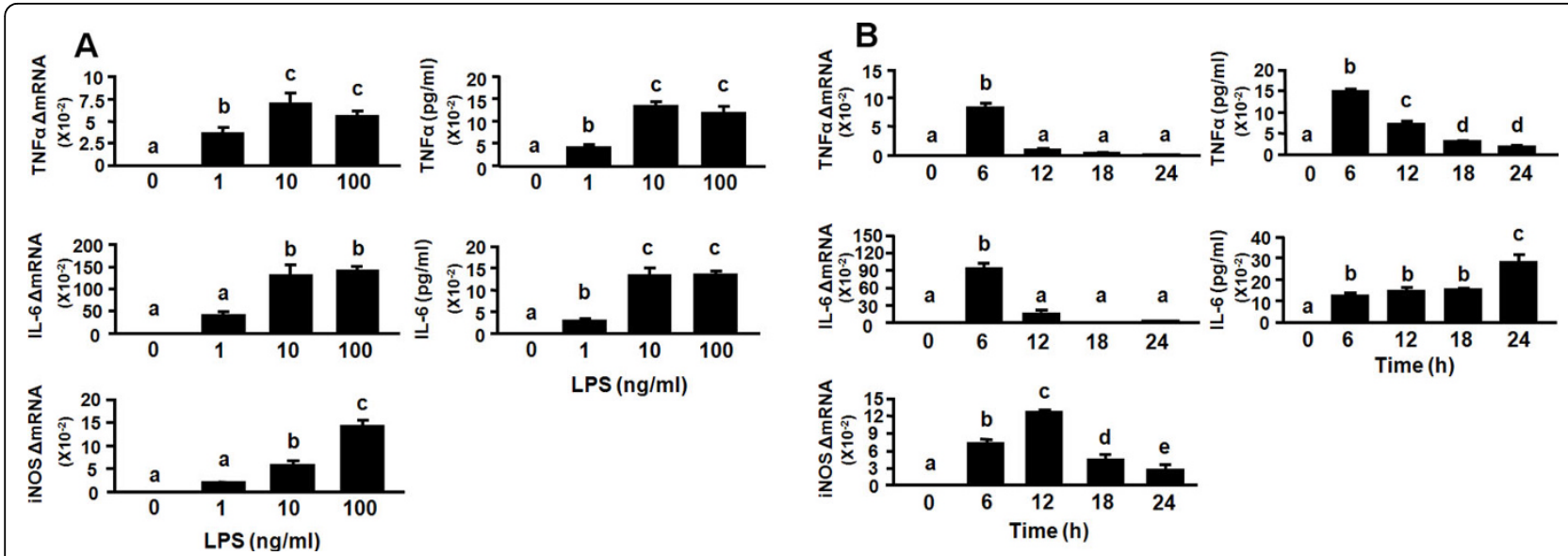

Figure 5 LPS induces proinflammatory cytokines and iNOS expression in OHSCs in a dose- and time-dependent manner. (A) 1,10 or $100 \mathrm{ng} / \mathrm{ml}$ LPS were added to the medium after 10 days in culture. Tissue and media were collected $6 \mathrm{~h}$ later. Average Ct values for 1,10 or $100 \mathrm{ng} / \mathrm{ml}$ LPS were, respectively, for TNFa: $20.6 \pm 0.6,19.6 \pm 0.5,19.6 \pm 0.6 ;$ IL-6: $24.1 \pm 0.6,22.5 \pm 0.6,22.1 \pm 0.6$; iNOS: 26.2 $\pm 0.9,24.9 \pm 1.0$, $23.6 \pm 0.9$. (B) Hippocampal slices were treated with LPS $(10 \mathrm{ng} / \mathrm{ml})$ and tissue and media were collected at various times. Average Ct values at 6, 12, 18 and $24 \mathrm{~h}$ were, respectively, for TNFa: $19.7 \pm 0.1,22.8 \pm 0.7,24.4 \pm 0.9,25.3 \pm 0.7$; IL-6: $23.2 \pm 0.3,24.9 \pm 0.7,28.1 \pm 1.1,28.8 \pm 0.7$; iNOS: $24.1 \pm 0.1,22.7 \pm 0.6,24.4 \pm 1.1,25.2 \pm 1.0$. Amount of the proinflammatory cytokines was measured by ELISA. Bars represent the mean \pm SEM ( $n=3$ in each group). Bars labeled with different letters $(a, b, c, d$ or e) are significantly different from each other at $p<0.05$.

of any detectable IFNg [37]. Here we used real-time RTPCR to determine whether LPS induces IDO steadystate transcripts in OHSCs as it does in vivo at $6 \mathrm{~h}$. To determine an optimal dose for LPS-induced expression of IDO, OHSCs were treated with 1,10 and $100 \mathrm{ng} / \mathrm{ml}$ of LPS for $6 \mathrm{~h}$. As shown in Fig. 6A, IDO mRNA expression could be detected at $1 \mathrm{ng} / \mathrm{ml}$ LPS and reached a maximum at $10 \mathrm{ng} / \mathrm{ml}$ LPS $(p<0.05)$. Kinetic studies were then carried out in which OHSCs were exposed to LPS $(10 \mathrm{ng} / \mathrm{ml})$ for $6,12,18$ and $24 \mathrm{~h}$. Figure $6 \mathrm{~B}$ shows that IDO mRNA could not be detected in OHSCs prior to addition of LPS (40 amplification cycles). However, IDO expression was strongly but transiently induced by LPS at $6 \mathrm{~h}(p<0.01)$, returning to the same level as time 0 by $12 \mathrm{~h}$. Importantly, this LPSinduced expression of IDO did not require endogenous synthesis of IFNg because no IFNg mRNA could be detected at any time point in LPS-stimulated slices (40 amplification cycles, data not shown). Similarly, we found that LPS did not cause a statistically significant increase in IFNg mRNA expression at the earlier time point of $2 \mathrm{~h}$ (data not shown). This finding using OHSCs is consistent with the results of recent studies reporting that IFNg-independent mechanisms can mediate IDO induction in hippocampal neurons [45] and primary murine microglial cells [37].

\section{LPS increases IDO enzymatic activity in OHSCs}

To assess whether OHSCs express functional IDO, we determined IDO enzymatic activity by measuring the amount of kynurenine formed following incubation of OHSCs lysates with exogenous L-tryptophan (Fig. 6C).
These experiments showed that IDO enzymatic activity increased with time following exposure to LPS. IDO enzymatic activity was augmented by LPS at $8 \mathrm{~h}(p<$ 0.01 ), and this functional activity remained elevated at 12 and $18 \mathrm{~h}(p<0.01)$ of culture compared to medium control. By $24 \mathrm{~h}$, IDO enzymatic activity returned to baseline. These findings are consistent with our previous data showing that LPS-induced increases in brain IDO mRNA precede activation of IDO and are associated with increased IDO enzymatic activity in vivo [14] and in primary murine microglia [37].

\section{Discussion}

Experiments in this report were designed to answer three major questions: (1) Can a direct central challenge with LPS activate IDO in the hippocampus and induce depressive-like behavior? (2) Can a murine organotypic culture system serve as a reliable in situ model for investigating mechanistic aspects of the depressive effects of inflammation? (3) Does this in situ model of OHSCs respond like primary microglia in vitro where IDO induction can occur via an IFNg-independent mechanism? To our knowledge, this is the first report to demonstrate that centrally administered LPS induces depressive-like behavior as measured by increased immobility in the forced swim test after sickness behavior has dissipated and this effect is associated with IDO activation. Furthermore, the effect of LPS on IDO production in vivo translates to the in situ setting, and IDO activation in response to LPS occurs in the absence of up-regulation of transcripts for IFNg. Thus, murine OHSCs can be reliably used to study the mechanisms of 


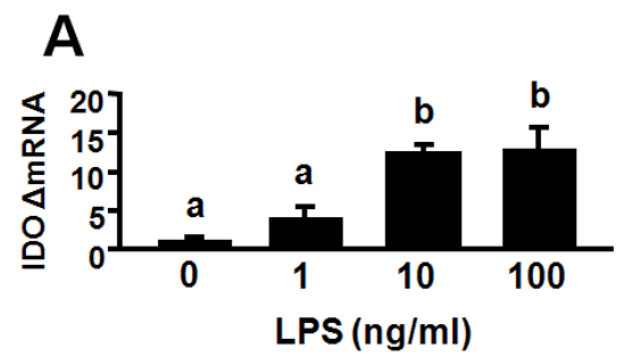

C
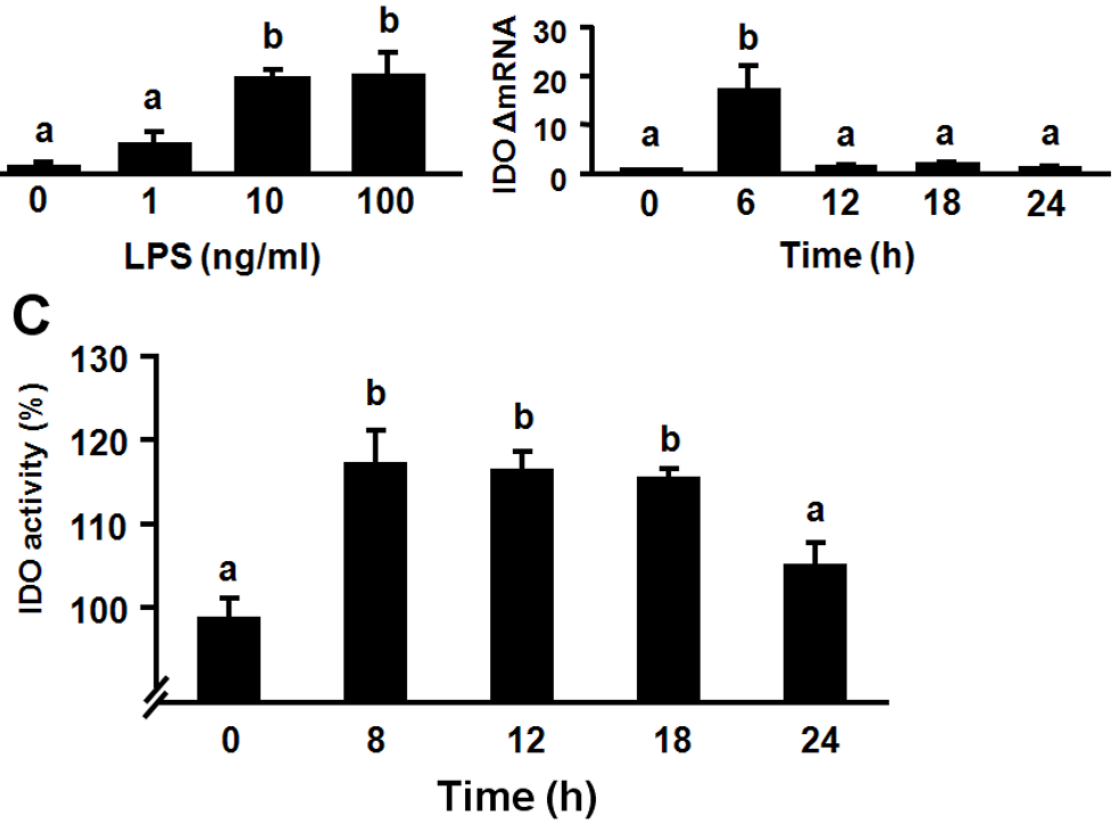

Figure 6 LPS increases IDO mRNA and enzymatic activity in OHSCs. (A) 1, 10 or $100 \mathrm{ng} / \mathrm{ml}$ LPS were added to the medium after 10 days in culture. Tissue and media were collected $6 \mathrm{~h}$ following addition of LPS. Average Ct values for $1,10 \mathrm{or} 100 \mathrm{ng} / \mathrm{ml}$ LPS for IDO were, respectively, $38.4 \pm 0.8,36.4 \pm 0.3,36.4 \pm 0.3$. (B) Hippocampal slices were treated with LPS $(10 \mathrm{ng} / \mathrm{ml})$ for various times. Average Ct values at $6,12,18$ and $24 \mathrm{~h}$ for IDO were, respectively, $36.7 \pm 0.4,39.5 \pm 0.5,39.7 \pm 0.4,40 \pm 0$. (C) Hippocampal slices were treated with LPS (10 $\mathrm{ng} / \mathrm{ml}) \mathrm{for} 8,12,18$ and $24 \mathrm{~h}$. IDO enzymatic activity was determined by measuring the amount of kynurenine formed upon incubation of slices lysates with exogenous L-tryptophan. IDO enzymatic activity was expressed as a percentage of the medium control. Bars labeled with different letters (a or b) are significantly different from each other at $p<0.05$.

cytokine-induced activation of IDO without interference of cytokine synthesis due to preparation of the slices.

Activation of brain cytokine signaling in response to peripheral or central administration of LPS has repeatedly been demonstrated to mediate LPS-induced sickness behavior $[2,6,46]$. In the present study, i.c.v. LPS induced sickness behavior, as measured by body weight loss and decreased social exploration, and this effect was associated with increased expression of steady-state transcripts for TNFa, IL-6, iNOS and IDO in the hippocampus. Moreover, i.c.v. administration of LPS was sufficient to induce depressive-like behavior, as measured by increased immobility in the forced swim test when social exploration had dissipated. These results are an important conceptual advance since the association between LPS-induced depressive-like behavior and activation of hippocampal IDO indicates that kynurenine does not need to enter the brain from the periphery to induce depressive-like behavior.

The choice of the hippocampus as a target structure for ex vivo analysis of cytokine expression in response to
LPS was not motivated by consideration of the possible role of this brain area in major depressive disorders $[27,47,48]$ but by the need to compare ex vivo data to in situ data collected in OHSCs. Compared to primary cultures of brain cells, OHSCs have the advantage of conserving some form of neuroanatomical organization together with functional cell-to-cell interactions [32,33]. OHSCs recreate an intact brain microenvironment that preserves the cytoarchitecture and functional information-processing properties of neurons. The morphological characteristics of neurons and glial cells in hippocampal slice cultures have been studied by both light and electron microscopy. During slice preparation, cutting of afferent and efferent axons inevitably leads to a rearrangement of connectivity over the following days. Most cells on the slice surface are healthy, receiving and sending inputs from intact axons, and both increased excitatory miniature synaptic current frequency and dendritic complexity are established within the first week of culture [49]. During the first 2 days of culture, astrocytes appear thin and elongated in the rat system. 
Over the next 8 days, astrocytes become hypertrophic and form a gliotic scar over the surface of the culture. "Reactive/activated" microglia reaches peak numbers immediately after injury induced by culture preparation. These ameboid microglia are replaced after 10 days in culture by "resting/ramified" microglia [50]. Since long term organotypic cultures of the murine hippocampi have been rarely used in neuroimmunology, it was necessary first to validate this model system. The early but transient increases in TNFa and IL-6 expression and release in response to the traumatic injury caused by transversal sectioning probably originated from activated microglial cells. After several days in vitro, the decline in the production of cytokines to baseline almost certainly reflected the return of microglia to their non-activated phenotype. However, this conclusion still needs to be confirmed using appropriate techniques.

Most dead cells disappeared and cytokines could no longer be detected in the culture medium after the first week of culture. This finding indicates that the inflammatory profile has certainly subsided, such that murine OHSCs can be safely used as soon as after 7 days in culture. In the rat system, the optimal time window for experiments is between day 6 and day 18 [51]. At this time, most of the slices are healthy and vital. After this time, the percentage of usable slices decreases, but viable rat OHSCs can last a minimum of 6-8 weeks in culture [51]. In the present conditions of murine OHSCs, LPS evoked a substantial expression of mRNA as well as the synthesis and release of TNFa and IL-6. These data confirm results previously reported in rat OHSCs [52]. It is important to note that the concentration of LPS-induced TNFa and IL-6 production were significantly higher than the levels measured at the onset of the organotypic culture.

Glial cells are the main sources of cytokines in CNS injury and inflammation [53]. TNFa produced at the earlier time point of $6 \mathrm{~h}$ probably originates from activated microglia whereas the peak in IL- 6 that occurred at $24 \mathrm{~h}$ is produced by astrocytes that are subsequently activated by TNFa [53]. We did not report changes in IL-1b mRNA or protein in OHSCs since the release of IL-1b in the culture medium requires the addition of ATP (data not shown). This implies that the production of IL-6 was likely solely dependent on TNFa production.

We were most interested in the potential use of murine OHSCs to determine whether LPS can activate IDO in this in situ system. We previously demonstrated that IDO, the first and rate-limiting enzyme in the synthesis of kynurenine from the precursor of tryptophan, is a required mediator of depressive-like behavior in response to LPS in mice [14]. The increase in brain IDO activity is invariably preceded by enhanced expression of IDO mRNA, which can therefore be used as a surrogate marker of IDO activation [14,37]. Expression and activation of IDO in response to LPS and other stimuli are usually studied in various types of transformed and primary cell cultures. However, murine OHSCs cultures have never been used for this purpose despite their potential advantages for the study of the intricate cell-to-cell communication mechanisms that mediate activation of IDO in the brain. In situ hybridization studies of the expression of IDO in the brain in response to LPS indicate that endothelial cells are the likely source of brain IDO [14] whereas immunohistochemistry findings point to a possible neuronal localization [54]. IDO is expressed in all types of brain cells that have been studied so far, including endothelial cells, glia and neurons [18]. The fate of IDO-produced kynurenine is not the same in microglia and other cell types because of differences in the intracellular enzymes that metabolize kynurenine [20]. Therefore, it is obviously important to determine in future experiments which brain cell types are predominantly involved in the production and degradation of kynurenine in response to an immune stimulus.

IFNg is considered to be the prototypical inducer of IDO in a variety of cell types [55] as well as in clinical situations in which inflammation-associated depression occurs [11]. However, IFNg-independent activation pathways have also been reported in response to LPS $[56,57]$. LPS-induced upregulation of IDO in the brain parallels increased IFNg mRNA expression in vivo [14] but whether this leads to increased mature IFNg protein can be disputed [58]. This does not mean that brain macrophages and microglia are capable of producing IFNg in other circumstances, even if most IFNg is normally produced by $\mathrm{T}$ lymphocytes and NK cells [59].

In conclusion, results of the present study clearly demonstrate that direct, central activation of brain cytokine signaling and IDO is associated with development of depressive-like behavior in the mouse. These results provide further arguments for the targeting of brain IDO to alleviate inflammation-associated depression.

\section{Acknowledgements}

The authors thank: Dr. Richard J. Miller (Northwestern University Medical School) for assistance in developing murine organotypic hippocampal slice cultures; Morgan L. Moon for assistance in collecting the in vivo data; Marc Lawson and Kelli Pankau for measurement of IDO enzymatic activity. The authors have no conflicting financial interests. Supported by $\mathrm{NIH}$ grants to KWK (R01 AG 029573) and RD (R01 MH 079829).

\section{Author details}

'Integrative Immunology and Behavior Program, Department of Animal Sciences, College of ACES, University of Illinois at Urbana-Champaign,

Urbana, Illinois 61801, USA. 'Department of Pathology, College of Medicine, University of Illinois at Urbana-Champaign, Urbana, Illinois 61801-3873, USA. ${ }^{3}$ Laboratory of Neuroimmunology and Developmental Origins of Disease (NIDOD), University Medical Center Utrecht, 3584 EA Utrecht, The Netherlands. 


\section{Authors' contributions}

XF and SMZ developed the technical procedures for OHSCs, assisted by advice on treatment application from JCO and AK. JCO was responsible for analyzing the in vivo component of these experiments. XF designed the experiments with the help of RD and KWK, performed the OHSCs experiments, analyzed the results and drafted the manuscript. RD and KWK secured funding for the project and helped with the final version of the manuscript. All authors read and approved the final manuscript.

\section{Competing interests}

$\mathrm{RD}$ has received honorarium from Astra-Zeneca, Bristol-Myers-Squibb and Lundbeck Laboratories. He is working as a consultant for Lundbeck Laboratories. KWK has received honorarium from Astra-Zeneca.

Received: 16 July 2010 Accepted: 2 August 2010

Published: 2 August 2010

\section{References}

1. Maier SF, Watkins LR: Cytokines for psychologists: implications of bidirectional immune-to-brain communication for understanding behavior, mood, and cognition. Psychological Review 1998, 105:83-107.

2. Dantzer R, O'Connor JC, Freund GG, Johnson RW, Kelley KW: From inflammation to sickness and depression: when the immune system subjugates the brain. Nature Reviews Neuroscience 2008, 9:46-56.

3. Raison $C L$, Capuron L, Miller AH: Cytokines sing the blues: inflammation and the pathogenesis of depression. Trends in Immunology 2006, 27:24-31.

4. Maes M: Major depression and activation of the inflammatory response system. Advances in Experimental Medicine and Biology 1999, 461:25-46.

5. Yirmiya R, Weidenfeld J, Pollak Y, Morag M, Morag A, Avitsur R, Barak O, Reichenberg A, Cohen E, Shavit Y, Ovadia H: Cytokines, "depression due to a general medical condition," and antidepressant drugs. Advances in Experimental Medicine and Biology 1999, 461:283-316.

6. Kelley KW, Bluthe RM, Dantzer R, Zhou JH, Shen WH, Johnson RW, Broussard SR: Cytokine-induced sickness behavior. Brain Behavior and Immunity 2003, 17(Suppl 1):S112-118.

7. Wichers MC, Maes M: The role of indoleamine 2,3-dioxygenase (IDO) in the pathophysiology of interferon-alpha-induced depression. Journal of Psychiatry \& Neuroscience 2004, 29:11-17.

8. Fitzgerald P, Cassidy Eugene M, Clarke G, Scully P, Barry S, Quigley Eamonn MM, Shanahan F, Cryan J, Dinan Timothy G: Tryptophan catabolism in females with irritable bowel syndrome: relationship to interferon-gamma, severity of symptoms and psychiatric co-morbidity. Neurogastroenterology \& Motility 2008, 20:1291-1297.

9. Neumeister A: Tryptophan depletion, serotonin, and depression: where do we stand? Psychopharmacology Bulletin 2003, 37:99-115.

10. Kohl C, Sperner-Unterweger B: IDO and clinical conditions associated with depressive symptoms. Current Drug Metabolism 2007, 8:283-287.

11. Widner B, Leblhuber F, Fuchs D: Increased neopterin production and tryptophan degradation in advanced Parkinson's disease. Journal of Neural Transmission 2002, 109:181-189.

12. Raison CL, Dantzer R, Kelley KW, Lawson MA, Woolwine BJ, Vogt G, Spivey JR, Saito K, Miller AH: CSF concentrations of brain tryptophan and kynurenines during immune stimulation with IFN-alpha: relationship to CNS immune responses and depression. Molecular Psychiatry 2010, 15:393-403.

13. Capuron L, Ravaud A, Neveu PJ, Miller AH, Maes M, Dantzer R: Association between decreased serum tryptophan concentrations and depressive symptoms in cancer patients undergoing cytokine therapy. Molecular Psychiatry 2002, 7:468-473.

14. O'Connor JC, Lawson MA, Andre C, Moreau M, Lestage J, Castanon N, Kelley KW, Dantzer R: Lipopolysaccharide-induced depressive-like behavior is mediated by indoleamine 2,3-dioxygenase activation in mice. Molecular Psychiatry 2009, 14:511-522.

15. O'Connor JC, Andre C, Wang Y, Lawson MA, Szegedi SS, Lestage J, Castanon N, Kelley KW, Dantzer R: Interferon-gamma and tumor necrosis factor-alpha mediate the upregulation of indoleamine 2,3-dioxygenase and the induction of depressive-like behavior in mice in response to bacillus Calmette-Guerin. The Journal of Neuroscience 2009, 29:4200-4209.

16. O'Connor JC, Lawson MA, Andre C, Briley EM, Szegedi SS, Lestage J, Castanon N, Herkenham M, Dantzer R, Kelley KW: Induction of IDO by bacille Calmette-Guerin is responsible for development of murine depressive-like behavior. Journal of Immunology 2009, 182:3202-3212.

17. Myint AM, Schwarz MJ, Steinbusch HW, Leonard BE: Neuropsychiatric disorders related to interferon and interleukins treatment. Metabolic Brain Disease 2009, 24:55-68.

18. Guillemin GJ, Smythe G, Takikawa O, Brew BJ: Expression of indoleamine 2,3-dioxygenase and production of quinolinic acid by human microglia, astrocytes, and neurons. Glia 2005, 49:15-23.

19. Muller N, Schwarz MJ: The immune-mediated alteration of serotonin and glutamate: towards an integrated view of depression. Molecular Psychiatry 2007, 12:988-1000.

20. Schwarcz R, Pellicciari R: Manipulation of brain kynurenines: glial targets, neuronal effects, and clinical opportunities. The Journal of Pharmacology and Experimental Therapeutics 2002, 303:1-10.

21. Frenois F, Moreau M, O'Connor J, Lawson M, Micon C, Lestage J, Kelley KW, Dantzer R, Castanon N: Lipopolysaccharide induces delayed FosB/ DeltaFosB immunostaining within the mouse extended amygdala, hippocampus and hypothalamus, that parallel the expression of depressive-like behavior. Psychoneuroendocrinology 2007, 32:516-531.

22. Henry CJ, Huang Y, Wynne A, Hanke M, Himler J, Bailey MT, Sheridan JF, Godbout JP: Minocycline attenuates lipopolysaccharide (LPS)-induced neuroinflammation, sickness behavior, and anhedonia. Journal of Neuroinflammation 2008, 13:5-15.

23. Miller JM, MacGarvey U, Beal MF: The effect of peripheral loading with kynurenine and probenecid on extracellular striatal kynurenic acid concentrations. Neuroscience Letters 1992, 146:115-118.

24. Kaper T, Looger LL, Takanaga H, Platten M, Steinman L, Frommer WB: Nanosensor detection of an immunoregulatory tryptophan influx/ kynurenine efflux cycle. PLoS Biology 2007, 5:e257.

25. TM P: Linking the cytokine and neurocircuitry hypotheses of depression: a translational framework for discovery and development of novel antidepressants. Brain Behavior and Immunity 2010, 24:515-524.

26. Campbell SMG: The role of the hippocampus in the pathophysiology of major depression. Journal of Psychiatry \& Neuroscience 2004, 29:417-426.

27. McKinnon MC, Yucel K, Nazarov A, MacQueen GM: A meta-analysis examining clinical predictors of hippocampal volume in patients with major depressive disorder. Journal of Psychiatry \& Neuroscience 2009, 34:41-54.

28. Eisch AJ, Cameron H, Encinas JM, Meltzer LA, Ming GL, OverstreetWadiche LS: Adult neurogenesis, mental health, and mental illness: hope or hype? The Journal of Neuroscience 2008, 28:11785-11791.

29. Andre C, O'Connor JC, Kelley KW, Lestage J, Dantzer R, Castanon N: Spatiotemporal differences in the profile of murine brain expression of proinflammatory cytokines and indoleamine 2,3-dioxygenase in response to peripheral lipopolysaccharide administration. Journal of Neuroimmunology 2008, 200:90-99.

30. Moreau M, Andre C, O'Connor JC, Dumich SA, Woods JA, Kelley KW, Dantzer R, Lestage J, Castanon N: Inoculation of Bacillus Calmette-Guerin to mice induces an acute episode of sickness behavior followed by chronic depressive-like behavior. Brain Behavior and Immunity 2008, 22:1087-1095.

31. Connor TJ, Starr N, O'Sullivan JB, Harkin A: Induction of indolamine 2,3 dioxygenase and kynurenine 3-monooxygenase in rat brain following a systemic inflammatory challenge: a role for IFN-gamma? Neuroscience Letters 2008, 441:29-34

32. Holopainen IE: Organotypic hippocampal slice cultures: a model system to study basic cellular and molecular mechanisms of neuronal cell death, neuroprotection, and synaptic plasticity. Neurochemical Research 2005, 30:1521-1528.

33. Noraberg J, Poulsen FR, Blaabjerg M, Kristensen BW, Bonde C, Montero M, Meyer M, Gramsbergen JB, Zimmer J: Organotypic hippocampal slice cultures for studies of brain damage, neuroprotection and neurorepair. Current Drug Targets, CNS Neurological Disorders 2005, 4:435-452.

34. Butler MP, O'Connor JJ, Moynagh PN: Dissection of tumor-necrosis factoralpha inhibition of long-term potentiation (LTP) reveals a p38 mitogenactivated protein kinase-dependent mechanism which maps to earlybut not late-phase LTP. Neuroscience 2004, 124:319-326.

35. Lonergan PE, Martin DS, Horrobin DF, Lynch MA: Neuroprotective actions of eicosapentaenoic acid on lipopolysaccharide-induced dysfunction in rat hippocampus. Journal of Neurochemistry 2004, 91:20-29. 
36. Fujigaki S, Saito K, Sekikawa K, Tone S, Takikawa O, Fujii H, Wada H, Noma A, Seishima M: Lipopolysaccharide induction of indoleamine 2,3dioxygenase is mediated dominantly by an IFN-gamma-independent mechanism. European Journal of Immunology 2001, 31:2313-2318.

37. Wang YX, Lawson MA, Dantzer R, Kelley KW: LPS-induced indoleamine 2,3 dioxygenase is regulated in an interferon-gamma-independent manner by a JNK signaling pathway in primary murine microglia. Brain Behavior and Immunity 2010, 24:201-209.

38. Palin K, Bluthe RM, McCusker RH, Levade T, Moos F, Dantzer R, Kelley KW: The type 1 TNF receptor and its associated adapter protein, FAN, are required for TNFalpha-induced sickness behavior. Psychopharmacology (Berl) 2009, 201:549-556.

39. Belmadani A, Tran PB, Ren D, Miller RJ: Chemokines regulate the migration of neural progenitors to sites of neuroinflammation. The Journal of Neuroscience 2006, 26:3182-3191.

40. Lestage J, Verrier D, Palin K, Dantzer R: The enzyme indoleamine 2,3dioxygenase is induced in the mouse brain in response to peripheral administration of lipopolysaccharide and superantigen. Brain Behavior and Immunity 2002, 16:596-601.

41. Dantzer R, Gheusi G, Johnson RW, Kelley KW: Central administration of insulin-like growth factor-1 inhibits lipopolysaccharide-induced sickness behavior in mice. Neuroreport 1999, 10:289-292.

42. Burgess W, Gheusi G, Yao J, Johnson RW, Dantzer R, Kelley KW: Interleukin1 beta-converting enzyme-deficient mice resist central but not systemic endotoxin-induced anorexia. The American Physiological Society 1998, 274 R1829-1833

43. Yao JH, Ye SM, Burgess W, Zachary JF, Kelley KW, Johnson RW: Mice deficient in interleukin-1 beta converting enzyme resist anorexia induced by central lipopolysaccharide. The American Physiological Society 1999, 277: R1435-1443.

44. Bonde C, Noraberg J, Zimmer J: Nuclear shrinkage and other markers of neuronal cell death after oxygen-glucose deprivation in rat hippocampal slice cultures. Neuroscience Letters 2002, 327:49-52.

45. Hoshi M, Saito K, Murakami Y, Taguchi A, Fujigaki H, Tanaka R, Takemura M, Ito $H$, Hara A, Seishima M: Marked increases in hippocampal neuron indoleamine 2, 3-dioxygenase via IFN-gamma-independent pathway following transient global ischemia in mouse. Neuroscience Research 2009, 63:194-198.

46. Dantzer R, Kelley KW: Twenty years of research on cytokine-induced sickness behavior. Brain Behavior and Immunity 2007, 21:153-160.

47. Schmidt HD, Duman RS: The role of neurotrophic factors in adult hippocampal neurogenesis, antidepressant treatments and animal models of depressive-like behavior. Behavioural Pharmacology 2007, 18:391-418.

48. Sahay A, Drew MR, Hen R: Dentate gyrus neurogenesis and depression. Progress in Brain Research 2007, 163:697-722.

49. De Simoni A, Griesinger CB, Edwards FA: Development of rat CA1 neurones in acute versus organotypic slices: role of experience in synaptic morphology and activity. The Physiological Society 2003, 550:135-147.

50. Ide CF, Scripter JL, Coltman BW, Dotson RS, Snyder DC, Jelaso A: Cellular and molecular correlates to plasticity during recovery from injury in the developing mammalian brain. Progress in Brain Research 1996, 108:365-377.

51. De Simoni A, Yu LM: Preparation of organotypic hippocampal slice cultures: interface method. Nature Protocols 2006, 1:1439-1445.

52. Huuskonen J, Suuronen T, Miettinen R, van Groen T, Salminen A: A refined in vitro model to study inflammatory responses in organotypic membrane culture of postnatal rat hippocampal slices. Journal of Neuroinflammation 2005, 15:2-25.

53. Benveniste E: Inflammatory cytokines within the central nervous system sources, function, and mechanism of action. The American Physiological Society 1992, 263:C1-16.

54. Roy EJ, Takikawa O, Kranz DM, Brown AR, Thomas DL: Neuronal localization of indoleamine 2,3-dioxygenase in mice. Neuroscience Letters 2005, 387:95-99

55. Taylor MW, Feng GS: Relationship between interferon-gamma, indoleamine 2,3-dioxygenase, and tryptophan catabolism. The FASEB Journal 1991, 5:2516-2522.

56. Fujigaki HSK, Fujigaki S, Takemura M, Sudo K, Ishiguro H, Seishima M: The signal transducer and activator of transcription 1alpha and interferon regulatory factor 1 are not essential for the induction of indoleamine 2,3-dioxygenase by lipopolysaccharide: involvement of p38 mitogenactivated protein kinase and nuclear factor-kappaB pathways, and synergistic effect of several proinflammatory cytokines. The Journal of Biochemistry 2006, 139:655-662.

57. Jung ID, Lee CM, Jeong YI, Lee JS, Park WS, Han J, Park YM: Differential regulation of indoleamine 2,3-dioxygenase by lipopolysaccharide and interferon gamma in murine bone marrow derived dendritic cells. FEBS Letters 2007, 581:1449-1456.

58. Roche M, Diamond M, Kelly JP, Finn DP: In vivo modulation of LPSinduced alterations in brain and peripheral cytokines and HPA axis activity by cannabinoids. Journal of Neuroimmunology 2006, 181:57-67.

59. Suzuki $Y$, Claflin J, Wang $X$, Lengi A, Kikuchi T: Microglia and macrophages as innate producers of interferon-gamma in the brain following infection with Toxoplasma gondii. International Journal for Parasitology 2005, 35:83-90.

doi:10.1186/1742-2094-7-43

Cite this article as: Fu et al:: Central Administration of

Lipopolysaccharide Induces Depressive-like Behavior in Vivo and Activates Brain Indoleamine 2,3 Dioxygenase In Murine Organotypic Hippocampal Slice Cultures. Journal of Neuroinflammation 2010 7:43.

\section{Submit your next manuscript to BioMed Central and take full advantage of:}

- Convenient online submission

- Thorough peer review

- No space constraints or color figure charges

- Immediate publication on acceptance

- Inclusion in PubMed, CAS, Scopus and Google Scholar

- Research which is freely available for redistribution
Ciomed Central 